\title{
POR UM MODELO PEDAGÓGICO PARA UMA EDUCAÇÃO AGROECOLÓGICA EM PERSPECTIVA CAMPONESA E INDÍGENA: AVANÇOS, TENSÕES E DESAFIOS NO BRASIL E NO MÉXICO
}

\author{
POR UM MODELO PEDAGÓGICO PARA UNA EDUCACIÓN AGROECOLÓGICA EN \\ PERSPECTIVA CAMPESINA E INDÍGENA: AVANCES, TENSIONES Y DESAFÍOS \\ EN BRASIL Y EN MÉXICO
}

\author{
TOWARDS A PEDAGOGICAL MODEL FOR AGROECOLOGICAL EDUCATION \\ FROM A PEASANT AND INDIGENOUS PERSPECTIVE: ADVANCES, TENSIONS \\ AND CHALLENGES IN BRAZIL AND MEXICO
}

\author{
Rosa LÓPEZ VALENTÍN ${ }^{1}$ \\ Peter Michael ROSSET ${ }^{2}$ \\ Lia PINHEIRO BARBOSA ${ }^{3}$ \\ Carla Andreia LOBO CASTRO ${ }^{4}$
}

\begin{abstract}
RESUMO: O presente artigo apresenta a concepção, avanços, desafios e tensões que emergem da proposição de um modelo educativo-pedagógico para a agroecologia. Para tanto, apresentamos duas experiências educativas de microcontextos do México e do Brasil, articuladas por movimentos indígenas e camponeses: a Escola de Agricultura Ecológica $U$ YITS KA'AN, em Maní, Yucatán, México, e a Escola de Ensino Médio do Campo João dos Santos de Oliveira, uma escola do campo situada no Assentamento 25 de Maio, em Madalena, Ceará, Brasil. Apontamos a diversidade, complexidade e combinações que perpassam as estratégias dos sujeitos na reivindicação da agroecologia no processo educativo e formativo de ambas as escolas, e suas interfaces na disputa de um modelo educativo atrelado ao contexto sócio-histórico da luta indígena e camponesa dos dois países.
\end{abstract}

PALAVRAS-CHAVE: Agroecologia. Educação. Modelos pedagógicos. Camponeses. Indígenas.

${ }^{1}$ El Colegio de la Frontera Sur (ECOSUR), San Cristóbal de Las Casas - Chiapas - México. Departamento de Agricultura, Sociedade e Meio Ambiente, membro do Grupo Acadêmico de Agroecologia, e do Grupo de Pesquisa sobre a Massificação da Agroecologia. ORCID: https://orcid.org/0000-0003-0691-245X. E-mail: rosalovale@gmail.com

${ }^{2}$ El Colegio de la Frontera Sur (ECOSUR), San Cristóbal de Las Casas - Chiapas - México. Professor Pesquisador Titular C no Departamento de Agricultura, Sociedade e Meio Ambiente, membro do Grupo Acadêmico de Agroecologia, e do Grupo de Pesquisa sobre a Massificação da Agroecologia. Pesquisador Visitante no Programa de Pós-Graduação em Sociologia (PPGS) da Universidade Estadual do Ceará (UECE). Doutorado em Filosofia (UMICH) - Estados Unidos. Bolsista BPV-FUNCAP. ORCID: https://orcid.org/00000002-1253-1066. E-mail: prosset@ecosur.mx

${ }^{3}$ Universidade Estadual do Ceará (UECE), Fortaleza - CE - Brasil. Docente no Programa de Pós-Graduação em Sociologia (PPGS) e no Mestrado Acadêmico Intercampi em Educação e Ensino (MAIE). Pesquisadora do CLACSO. Doutorado em Estudos Latino-Americanos (UNAM) - México. ORCID: https://orcid.org/0000-00030727-9027. E-mail: lia.barbosa@uece.br

${ }^{4}$ Universidade Estadual do Ceará (UECE), Fortaleza - CE - Brasil. Mestranda no Mestrado Acadêmico Intercampi em Educação e Ensino (MAIE). ORCID: https://orcid.org/0000-0003-3401-1560. E-mail: andreinacarla2005@yahoo.com.br

RIAEE - Revista Ibero-Americana de Estudos em Educação, Araraquara, v. 16, n. esp. 2, p. 1215-1230, maio 2021. e-ISSN: 1982-5587 
RESUMEN: Este artículo presenta la concepción, los avances, los desafíos y las tensiones que surgen de la propuesta de un modelo educativo-pedagógico para la agroecología. Para ello, presentamos dos experiencias educativas de microcontextos de México y Brasil, articuladas por movimientos indígenas y campesinos: la Escuela de Agricultura Ecológica $U$ YITS KA'AN, en Maní, Yucatán, México, y la Escuela del Campo João dos Santos, una escuela del campo ubicada en el Asentamiento 25 de Maio, en Madalena, Ceará, Brasil. Señalamos la diversidad, complejidad y combinaciones que impregnan las estrategias de los sujetos en la demanda de agroecología en el proceso educativo y formativo de ambas escuelas, y sus interfaces en la disputa por un modelo educativo vinculado al contexto sociohistórico de la lucha indígena y campesina en ambos países.

PALABRAS-CLAVE: Agroecología. Educación. Modelos pedagógicos. Campesinos. Indigenas.

ABSTRACT: This article presents the conception, advances, challenges and tensions that emerge from the proposal of an educational-pedagogical model for agroecology. For this, we present two educational experiences from micro-contexts in Mexico and Brazil, constructed by indigenous and peasant movements. One is the "U YITS KA'AN" Ecological Agriculture School, in Maní, Yucatán, Mexico, and the other is the São José High School, a rural school located in the 25 de Maio Settlement, in Madalena, Ceará, Brazil. We characterize the diversity, complexity, and combinations that permeate the strategies of the movements faced with the demand for agroecology education, and how these interface in the dispute for an educational model linked to the socio-historical context of the indigenous and peasant struggle in both countries.

KEYWORDS: Agroecology. Education. Pedagogical models. Peasants. Indigenous people.

\section{Introdução}

O presente artigo apresenta a concepção, avanços, desafios e tensões que emergem da proposição de um modelo educativo-pedagógico para a agroecologia. Para tanto, apresentamos duas experiências educativas de microcontextos do campo no México e no Brasil, que articulam organizações indígenas e camponeses: a Escola de Agricultura Ecológica $U$ YITS $K A^{\prime} A N$, em Maní, Yucatán, México, e a Escola de Ensino Médio do Campo João dos Santos de Oliveira, uma escola do campo situada no Assentamento 25 de Maio, em Madalena, Ceará, Brasil.

Apontamos a diversidade, complexidade e combinações que perpassam as estratégias dos sujeitos na reivindicação da agroecologia no processo educativo e formativo de ambas as escolas, e suas interfaces na disputa de um modelo educativo atrelado ao contexto sóciohistórico da luta indígena e camponesa dos dois países.

RIAEE - Revista Ibero-Americana de Estudos em Educação, Araraquara, v. 16, n. esp. 2, p. 1215-1230, maio 2021. e-ISSN: 1982-5587 
Para tanto, foi desenvolvida uma estratégia metodológica qualitativa, de caráter etnográfico, utilizando técnicas de investigação como a observação participante junto às escolas analisadas, bem como em outros espaços de articulação política construídos pelos sujeitos da pesquisa.

Além da introdução, o artigo está organizado em três seções: a primeira destina-se a apresentar as experiências educativas desenvolvidas em microcontextos no Brasil e no México, onde serão apresentadas as escolas analisadas. Na segunda seção, apresentamos as estratégias articuladas pelos sujeitos para a proposição de um modelo pedagógico para uma educação agroecológica e, na última seção, apontamos os desafios relacionados à disputa de um processo educativo na perspectiva indígena e camponesa.

\section{Experiências educativas em microcontextos do campo no México e no Brasil}

Em diferentes países latino-americanos encontramos experiências educativas de caráter local, nacional e regional em que o processo pedagógico é construído com vista a impulsionar o fortalecimento da identidade, da cultura, da subjetividade, do sentido de pertença ao território, ou ainda, de defesa do território como espaço de reprodução da vida, em uma perspectiva alternativa ao paradigma de desenvolvimento ocidental. Para fins da presente análise, apresentamos duas experiências que articulam organizações camponesas e indígenas, e desenvolvidas em dois microcontextos do campo no México e no Brasil: a Escola de Agricultura Ecológica U Yits Ka'na, um centro de formação agroecológica para indígenas camponeses maias, situada em Maní, no estado de Yucatán, México, e a Escola de Ensino Médio do Campo João dos Santos de Oliveira, uma escola do campo situada no Assentamento 25 de Maio, em Madalena, Ceará, Brasil.

Em ambas, encontramos uma aposta na construção de um modelo pedagógico para a educação em agroecologia, resultado de um processo político de defesa do território enquanto espaço de reprodução da vida, sob a ótica indígena e camponesa.

\section{A Escola de Agricultura Ecológica U Yits Ka'na}

No sul mexicano, no estado de Yucatán, encontra-se o município de Maní, onde se localiza a Escola de Agricultura Ecológica U Yits Ka'na (que na língua maia significa “orvalho que cai do céu”), criada nos anos 90 do século XX. Este município é um lugar emblemático da resistência maia, pois foi nele que teve lugar o “Auto de fé de Maní”, ocasião 
em que foram incinerados, em ato inquisitório, um número considerável dos códigos e imagens sagradas da cultura maia, em 12 de julho de 1562. O episódio histórico é considerado uma das cenas mais sangrentas da historiografia colonial no continente e expressão do epistemicídio provocado em contextos de colonização (GALEANO, 1991; SUÁREZ, 2014). Por esta razão, a existência da escola neste local é, em si, um ato de rebelião, persistência e resistência das populações maias contemporâneas.

Figura 1 - Localização da Escola de Agricultura Ecológica U Yits Ka'na

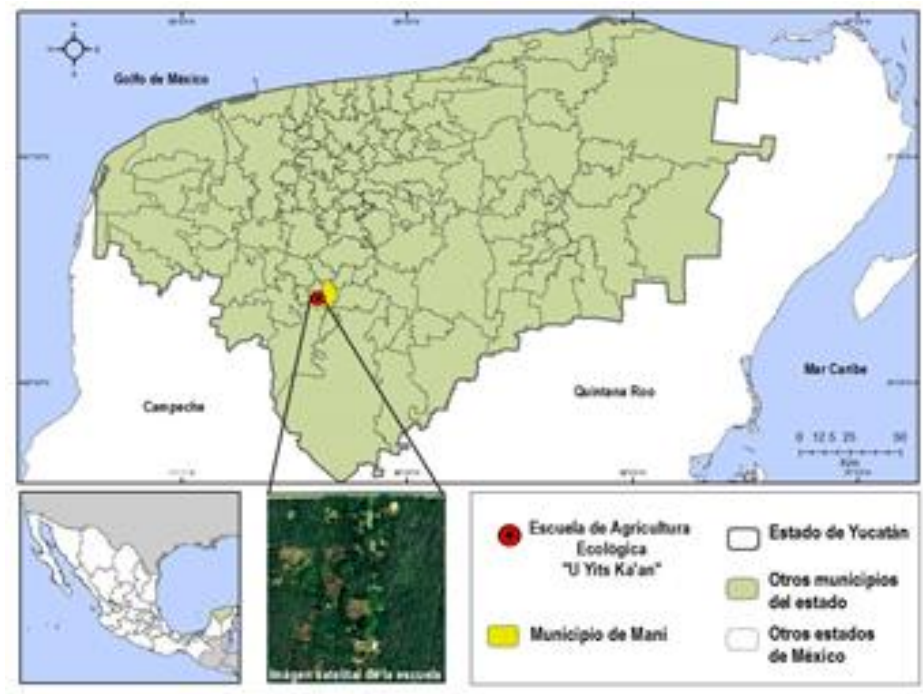

Fonte: Elaboração própria

No ano de 1991, um grupo de sacerdotes ligados à Teologia da Libertação e à Pastoral da Terra, que trabalhavam em várias localidades do estado de Yucatán, propôs a criação de um centro de formação para camponeses com o objetivo de promover processos sustentáveis de alternativas ao desenvolvimento, a partir de dois eixos: a revalorização da cultura tradicional e a agricultura ecológica (MACOSSAY et al., 2005). Tais sacerdotes tiveram contato com camponeses que participaram da criação do Método "Camponês a Camponês", uma metodologia social de territorialização da agroecologia criada na Guatemala e baseada na transmissão horizontal de conhecimentos agroecológicos, entre famílias camponesas, para a resolução de problemas de produção agropecuária e para o fomento de práticas agroecológicas (HOLT-JIMÉNEZ, 2008; MACHÍN-SOSA et al., 2013).

Em 1994, foi adquirido um terreno na periferia da capital municipal de Maní, graças ao financiamento da fundação alemã Misereor, uma instituição de cooperação internacional. Com os recursos disponíveis, foram construídas as infraestruturas necessárias para o funcionamento de uma escola. As instalações foram concluídas no final de 1995. Nesse mesmo ano, num esforço conjunto entre padres e professores de algumas universidades e 
ONGs, foi desenvolvido o primeiro currículo escolar (MACOSSAY et al., 2005). De 1996 a 2005, foram dadas aulas na escola aos camponeses da região, num sistema de semi-internato. Em 2005, o financiamento da Fundação Misereor chegou ao fim, tornando o sistema de internato inoperacional. Em 2009 foi criado um sistema de sub-escolas, com o objetivo de ter um maior contato com as comunidades da região, e de ter um vínculo mais próximo com as famílias rurais, estabelecendo centros de formação coordenados pelos próprios diplomados (HERNÁNDEZ, 2015). Muitos foram os atores internos, externos e aliados que a escola teve, entre os quais padres católicos, camponeses yucatecos e guatemaltecos maias, instituições educacionais, ONGs nacionais e internacionais, bem como outras fundações.

A escola $U$ Yits $K a^{\prime}$ an constitui uma escola de formação agroecológica ou escola de agroecologia. O processo de formação baseia-se na "aprendizagem significativa", que privilegia a prática sobre a teoria e valoriza os conhecimentos ancestrais da cultura indígena camponesa maia, baseada numa pedagogia de ensino "de camponês a camponês" (CEBALLOS, 2014). Nessa perspectiva, as escolas camponesas implicam uma forma alternativa de pensar, fazer e agir em relação à educação formal (MUÑOZ, 2013), uma vez que concebem o processo formativo em estreito vínculo com seus territórios. Os processos educativos e de formação relacionados com produtores, camponeses e povos indígenas procuram recuperar e reafirmar a importância do conhecimento local como contributo da sua própria intervenção perante uma proposta que inicialmente é disciplinar (técnica/produtiva), mas que mais tarde desenvolve uma reflexão coletiva e gera as condições para uma troca de conhecimentos em seus territórios.

Um exemplo disto é o diálogo construído com a Rede Nacional de Escolas Rurais, da qual a escola faz parte desde 2003. Esta rede funciona através de articulações regionais e a escola tem sido uma delas. A participação da Escola de Agricultura Ecológica U Yits Ka'na nestes espaços contribuiu para a discussão sobre a definição do conceito de escola rural e sobre quais devem ser os seus princípios orientadores. Nestes encontros, salienta-se a importância de valorizar a cultura e reafirmar a identidade camponesa e indígena. Do mesmo modo, constroem consenso em torno aos princípios que norteiam as mediações pedagógicas em contextos de escolas de campo, tais como espiritualidade, equidade, comunitarismo, comunidade, interculturalidade, ética, sustentabilidade e solidariedade, assumindo ao mesmo tempo o compromisso de defender e preservar a Mãe Terra e uma coexistência com a natureza (MATA, 2013)

Um dos principais princípios pedagógicos da escola é a libertação e descolonização dos camponeses da região maia com base no trabalho de reconstrução, ressignificação 
histórica e teológica; e que a partir desta base ideológica se incluem e transformam os conhecimentos técnicos, agroecológicos, florestais, artesanais e de medicina tradicional, entre muitas outras atividades, desenvolvidas por eles, em coerência com a vida comunitária. Nesse sentido, a estratégia da $U$ Yits $K a^{\prime} a n$ é a (re)construção comunitária, por meio do fomento do estudo da sua organização, articulação e inter-relação dos seus projetos com vista a uma ressignificação da identidade dos povos maias e os princípios do Ma'alob Kuxtal ou do bem viver para uma reconstrução da comunidade. ${ }^{5}$

No âmbito do fazer pedagógico da escola, a agroecologia tem sido utilizada como uma das principais ferramentas nesse processo de reconstrução do tecido social da comunidade. Contudo, o elemento crucial da escola é que a abordagem agroecológica não se limita à produção de alimentos, o que normalmente ocorre noutras escolas rurais onde os conhecimentos técnicos-produtivos são basicamente fornecidos para este fim. Desde o seu início na fase de internato, um dos eixos de formação foi o humano-social, que incluía a espiritualidade em sua vertente indígena maia, ou seja, a escola preocupava-se não só em fazer, mas também em ser. Isto tornou possível estabelecer um modelo alternativo que não partia de uma lógica produtiva; em vez disso, a escola procurou que os participantes se reconectassem com o seu ambiente e questionassem a sua realidade, partindo da reconfiguração da sua identidade com base no resgate da sua história como povos maias. Com base no exposto, afirmamos que a escola integra uma diversidade de propostas e caminhos pedagógicos que, a partir de uma aprendizagem significativa, na sua vida diária e na abordagem do cotidiano, se propõe a alcançar a construção da sociabilidade na comunidade.

As atividades da Escola de Agricultura Ecológica $U$ Yits Ka'na articulam três aspectos: Espiritual (E); Identificativo (I) e Produtivo (P). As duas primeiras têm uma relação direta com o fortalecimento da identidade e espiritualidade maias, sobretudo na reconfiguração da memória histórica no ambiente educativo. A terceira, articula-se ao fomento de uma educação agroecológica. Embora certas atividades sejam realizadas numa única dimensão, seja ela espiritual, identitária ou produtiva, a escola procura a inter-relação entre as dimensões. Estes processos de atividades produtivas-espirituais (SP), espiritual-identidade (IE), identitárioprodutivo (IP) e espiritual-identitário-produtivo (IPE) enriquecem a proposta educativa da escola. Por outro lado, a escola desenvolve uma abordagem pedagógica do seu calendário escolar em articulação com o calendário da vida comunitária, o qual contempla um enfoque histórico-ritual da cosmovisão e cultura maia como, por exemplo, a celebração do Dia de 
Xunán Kab (nome maia que designa a abelha sem ferrão), além do uso do calendário maia para a medicina tradicional.

Em suma, a estratégia pedagógica da escola é desenvolver atividades que correlacionem a identidade espiritual e comunitária com os aspectos produtivos. Isto reforça a sua convicção quanto à harmonia entre estes dois aspectos da formação humana, como uma forma de reconstruir um estilo de vida digno e pleno, isto é, conforme os princípios do bem viver, do Ma'alob Kuxtal, em oposição radical à abordagem produtivista e individualista, predominante na racionalidade capitalista.

Embora a Escola de Agricultura Ecológica U Yits Ka'na seja gerida por padres, articula diversas organizações, inclusive com forte incidência na luta indígena e camponesa mexicana, a exemplo de comunidades bases de apoio do Movimento Zapatista, da Pastoral Indígena, da União Nacional de Organizações Camponesas e Autônomas (UNORCA), organização membro da Via Campesina no México, e de outras organizações camponesas de Yucatán.

\section{A Escola de Ensino Médio do Campo João dos Santos de Oliveira}

Em 2010, no Ceará, o MST inicia o funcionamento das quatro primeiras escolas do campo destinadas à formação no ensino médio, resultado de uma pauta política de reivindicação, junto à Secretaria Estadual de Educação, de construção de escolas de Ensino Médio em áreas de assentamentos rurais. Como fruto dessa luta histórica, foram garantidas, inicialmente, quatro escolas do campo: ${ }^{6}$ E.E.M. João dos Santos de Oliveira (Escola do Campo João Sem Terra), no Assentamento 25 de Maio em Madalena-CE; E.E.M. Florestan Fernandes, no Assentamento Santana em Monsenhor Tabosa-CE; E.E.M. Nazaré Flor no Assentamento Maceió em Itapipoca-CE e E.E.M. Francisco Barros no Assentamento Lagoa do Mineiro em Itarema-CE. ${ }^{7}$ É importante destacar a participação das famílias assentadas em todo o processo de implementação das Escolas de Ensino Médio no Ceará, debatendo, ativamente, nas assembleias internas, nos espaços articulados pelo Setor de Educação e nas reuniões junto à Secretaria Estadual de Educação. Até a escolha do nome de cada escola foi feita por cada assentamento.

O MST celebrou, em 2020, 31 anos de existência no estado. É válido destacar que, originalmente, os processos de formação política das famílias camponesas no Ceará foram

${ }^{6}$ Atualmente são 10 Escolas de Ensino Médio do Campo em áreas de assentamentos rurais no Ceará, além de outras duas escolas que estão em construção.

7 Idem. 
impulsionados pela Pastoral da Terra e pela ala da Igreja Católica vinculada à Teologia da Libertação, notadamente das Comunidades Eclesiais de Base (CEBs). Nesse sentido, as primeiras ocupações de terra e a gênese do próprio MST no estado advém desse processo histórico. A preocupação com os processos educativos e formativos também se fez presente desde os acampamentos, tornando-se uma pauta política permanente do Setor de Educação e de Formação do MST (BARBOSA, 2015a).

As chamadas Escolas de Ensino Médio do Campo estão orientadas conforme os princípios educativos e pedagógicos da Educação do Campo e regidas a partir do marco regulatório da Política Nacional de Educação do Campo (BARBOSA, 2014; 2015b; 2016) e de uma agenda educativa articulada pelo Setor de Educação do MST, com destaque para: escola pública, gratuita e de qualidade para atender a demanda educativa em áreas de assentamentos rurais de reforma agrária do MST, desde a Educação Infantil à Educação Universitária; direito de estudar no próprio assentamento, acampamento, nas comunidades rurais; com uma proposta pedagógica voltada às questões da sua realidade e com educadores engajados neste contexto; escolas em condições de desenvolver o ensino técnico e a formação profissional para atuação no campo; gestão democrática dos processos educativos, com a participação efetiva das famílias Sem Terra assentadas; política específica para a seleção e formação de professores para a atuação nas escolas do campo em assentamentos e acampamentos; entre outros (MST-CE, 2012).

A Escola de Ensino Médio do Campo João dos Santos de Oliveira está localizada no Assentamento 25 de Maio, no município de Madalena/Ce. Este assentamento constitui a primeira área conquistada pelo MST no Ceará, com 22.992 hectares, associada ao número direto e indireto de famílias beneficiadas com a implantação da escola. O Assentamento 25 de Maio caracteriza-se por sua organicidade física e social, constituído de 428 famílias assentadas, aproximadamente 2.000 pessoas. Está dividido em 12 (doze) comunidades a partir de 1 Cooperativa, 18 associações e um Conselho Geral formado por representantes das associações da Cooperativa e do MST, que planejam e organizam a gestão geral do assentamento. O Conselho Geral tem como função discutir as questões políticas, organizativas, sociais, culturais, ambientais, educacionais e habitacionais das 428 famílias assentadas que vivem nas comunidades. ${ }^{8}$ 
Figura 2 - Localização geográfica do Assentamento 25 de Maio - Madalena/Ce

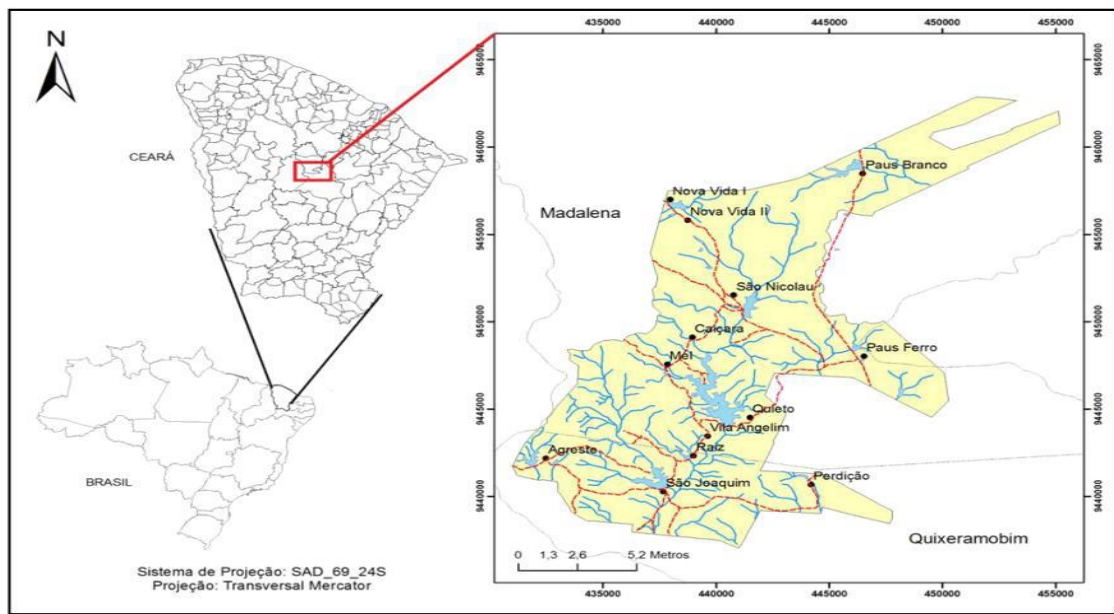

Fonte: Arquivos HIDROSED

A organização do trabalho pedagógico da Escola de Ensino Médio do Campo João dos Santos visa engendrar os princípios educativos e filosóficos da Pedagogia do Movimento (CALDART, 2004) e dos Complexos de Estudo (SAPELLI et al., 2015), baseados nos postulados da pedagogia soviética. Ademais, a escola possui uma estrutura curricular de caráter transversal, que articula três componentes curriculares integradores, a saber: Projetos, Estudos e Pesquisas (PEP), Organização do Trabalho e Técnicas Produtivas (OTTP) e Práticas Sociais Comunitárias (PSC), organizando pedagogicamente os conteúdos do currículo em sua articulação com a pesquisa, o trabalho e a intervenção social. Há uma diversidade de tempos educativos: Tempo formação e mística; Tempo aula; Tempo estudo individual; Tempo trabalho; Tempo oficina e atividades culturais; Tempo seminário; Tempo organicidade e Tempo esporte e lazer. A existência desses tempos educativos obedece ao fortalecimento da organicidade interna da escola e dela com as famílias assentadas e o próprio MST (PPP, 2010).

Cada Escola de Ensino Médio do Campo possui os denominados Campos Experimentais, uma área de 10 hectares integrada às escolas e destinadas à aprendizagem de práticas agroecológicas fomentadas pelos componentes curriculares integradores OTTP, PEP e PSC. A intencionalidade pedagógica do Setor de Educação do MST consiste em articular as escolas do campo ao processo de territorialização da agroecologia como uma estratégia de defesa dos territórios camponeses e de fortalecimento da agricultura camponesa e da reforma agrária popular. Para tanto, há um trabalho pedagógico e formativo articulado pelo Setor de Educação do MST para a inserção da agroecologia, seus princípios e metodologias de fomento na educação básica (CALDART et al., 2015; RIBEIRO et al., 2017; ROSSET, 2017), ao tempo que promove a territorialização da agroecologia por meio da Metodologia 
"De Camponês a Camponês" nos territórios camponeses do estado (FERNANDES; BARBOSA, 2020).

\section{Da interpelação do modelo educativo oficial à proposição de uma Educação Agroecológica}

Ao analisarmos processos educativos erigidos em microcontextos do campo, em particular no México e no Brasil, identificamos que ainda é um desafio para a Política Nacional de Educação de cada país atrelar a concepção de um processo educativo-pedagógico que atenda, plenamente, toda a demanda educativa, sobretudo em contextos rurais (BARBOSA, 2017; GÓMEZ-SOLLANO, 2017). Além disso, um dos principais desafios postos à gestão das políticas públicas em matéria educativa consiste em compreender que a concepção de educação advinda de organizações camponesas e indígenas não se limita à reivindicação do acesso à escola, ou mesmo da existência da escola e da educação formal em seus territórios. Essas organizações concebem a educação em um sentido omnilateral, de recuperação da humanização das relações sociais, em sentido freiriano, e de um processo formativo que reestabeleça o vínculo com a natureza. Com base nos dados coletados, elaboramos uma tabela dos eixos que articulam o modelo pedagógico das escolas em análise e suas diferenças frente ao padrão escolar da política nacional de educação dos países em questão. ${ }^{9}$

Quadro 1 - Eixos que articulam o modelo pedagógico das escolas

\begin{tabular}{|c|c|c|c|}
\hline $\begin{array}{l}\text { Eixos do modelo } \\
\text { pedagógico }\end{array}$ & $\begin{array}{l}\text { Escola de Agricultura } \\
\text { Ecológica } U \text { Yits } \\
K a^{\prime} n a\end{array}$ & $\begin{array}{l}\text { Escola de Ensino Médio do } \\
\text { Campo João dos Santos }\end{array}$ & Padrão escolar oficial \\
\hline $\begin{array}{l}\text { Estrutura e Função } \\
\text { da Escola }\end{array}$ & $\begin{array}{l}\text { Escola camponesa, de } \\
\text { caráter autônomo e } \\
\text { para a formação } \\
\text { agroecológica. }\end{array}$ & \begin{tabular}{llr}
\multicolumn{4}{l}{ Escola pública, ocupada por } \\
camponeses e & para a \\
formação na & educação \\
formal (Educação & do \\
Campo) e & para & a \\
agroecologia. & & \\
\end{tabular} & $\begin{array}{l}\text { Escola pública para a } \\
\text { formação na educação } \\
\text { formal e com uma Base } \\
\text { Nacional } \\
\text { Comum. Curricular } \\
\end{array}$ \\
\hline Perfil dos sujeitos & $\begin{array}{l}\text { Pertencentes às } \\
\text { comunidades indígenas } \\
\text { e camponesas, e com } \\
\text { interfaces com alguns } \\
\text { movimentos indígenas } \\
\text { e camponeses. }\end{array}$ & $\begin{array}{lr}\text { Pertencentes } & \text { aos } \\
\text { assentamentos de } & \text { reforma } \\
\text { agrária do MST. } & \end{array}$ & $\begin{array}{l}\text { Pertencentes a contextos } \\
\text { urbanos e rurais. }\end{array}$ \\
\hline Identidade coletiva & $\begin{array}{l}\text { Fortalecimento } \text { da } \\
\text { identidade maia } \\
\text { indígena e camponesa. }\end{array}$ & $\begin{array}{l}\text { Fortalecimento da identidade } \\
\text { camponesa. }\end{array}$ & $\begin{array}{lr}\text { Corresponde a uma } \\
\text { homogeneização } \\
\text { identidade articulada aos } \\
\text { princípios } & \text { da }\end{array}$ \\
\hline
\end{tabular}

${ }^{9}$ Em virtude dos limites de extensão do artigo, daremos ênfase às escolas, apontando os desafios destas frente à Política Nacional de Educação dos respectivos países.

RIAEE - Revista Ibero-Americana de Estudos em Educação, Araraquara, v. 16, n. esp. 2, p. 1215-1230, maio 2021. e-ISSN: 1982-5587 


\begin{tabular}{|l|l|l|lr|}
\hline & & & $\begin{array}{l}\text { modernidade ocidental } \\
\text { indivíduo } \\
\text { ao } \\
\text { cidadão/cidadã. }\end{array}$ \\
\hline Discurso motivador & $\begin{array}{l}\text { - Espiritualidade Maia; } \\
\text { - Bem Viver; } \\
\text { - Agroecologia. }\end{array}$ & $\begin{array}{l}\text { - Mística camponesa; } \\
\text { - Reforma Agrária Popular; } \\
\text { - Agroecologia. }\end{array}$ & $\begin{array}{l}\text { Formação para o } \\
\text { trabalho. }\end{array}$ \\
\hline $\begin{array}{l}\text { Projeto político- } \\
\text { pedagógico }\end{array}$ & $\begin{array}{l}\text { - Espiritualidade maia; } \\
\text { - Defesa do território e } \\
\text { dos comuns. }\end{array}$ & $\begin{array}{l}\text { - Educação do Campo; } \\
\text { Defesa do território } \\
\text { camponês e da soberania } \\
\text { alimentar }\end{array}$ & $\begin{array}{l}\text { Variável conforme cada } \\
\text { escola. }\end{array}$ \\
\hline
\end{tabular}

Fonte: Elaborado pelos autores

Os dados apresentados demonstram a diversidade, complexidade e combinações existentes em processos educativos de microcontextos do campo. Para o caso das experiências educativas analisadas, identificamos a construção de estratégias dos sujeitos na reivindicação da agroecologia em seu processo educativo e formativo. Essa reivindicação está atrelada aos processos sócio-históricos de defesa de seus territórios e reverbera na disputa de um modelo educativo articulado à trajetória histórica e às demandas políticas da luta indígena e camponesa dos dois países.

Argumentamos que os eixos estruturantes do modelo pedagógico de ambas as escolas apresentados acima, a saber, a estrutura e função da escola, o perfil dos sujeitos, a identidade coletiva, o discurso motivador e o projeto político-pedagógico da escola, requerem um processo permanente de elaboração de estratégias por parte dos sujeitos, no sentido de garantir a intencionalidade pedagógica de uma formação educativa para a agroecologia. Nesse sentido, observamos algumas estratégias comuns e, inclusive, também presentes em outros contextos educativos latino-americanos (BARBOSA; ROSSET, 2017): 1. A construção de uma concepção teórico-epistêmica da Educação como um projeto histórico de conhecimento; 2. A construção de uma teoria educativa e de um modelo pedagógico próprios; 3. A articulação política de organizações indígenas e camponeses no processo educativo e 4 . Agroecologia como matriz formativa.

É válido salientar o caráter de ocupação da escola para a sua transformação. No microcontexto do Brasil, o MST reconhece que a disputa por uma política pública de educação prescinde um processo de transformação da escola, uma vez que ela é moldada com base em uma formação pautada na racionalidade capitalista. Portanto, consideram que há uma ocupação da escola, primeiro passo para iniciar sua transformação em uma escola camponesa, cujo processo educativo contemple uma formação para a valorização do território camponês e de seu modo de ser e de viver.

Essas estratégias respondem à interpelação da racionalidade formativa no âmbito da Política Nacional de Educação, que visa um processo educativo concernente ao paradigma 
ocidental moderno capitalista, de homogeneização cultural, impulsionado pelos Estados nacionais e que, muitas vezes, não reconhece as diferenças regionais e sociais. No meio rural, historicamente, as políticas públicas para a educação, na sua grande maioria, não são elaboradas levando em consideração a realidade rural, uma vez que se mantém uma base nacional comum para o atendimento da demanda educativa nas duas realidades: urbana e rural. É importante ressaltarmos que a defesa de políticas públicas diferenciadas para as distintas realidades não significa que há uma superioridade de uma à outra e, sim, especificidades a serem consideradas.

Por outro lado, cada vez mais as organizações indígenas e camponesas reivindicam uma formação educativa para a permanência em seus territórios na defesa da vida comunitária, dos comuns, da autonomia, da soberania alimentar, todos considerados fundamentais para uma vida digna. Nesse sentido, a agroecologia emerge como matriz formativa, produtiva e projeto político de enfrentamento do capitalismo agrário no campo, construída em uma perspectiva politizada e a partir de um sujeito histórico. Por esta razão, essas experiências buscam desencadear um processo educativo agroecológico, que lhes permita fortalecer outra concepção de território e de relações humanas, em harmonia com a natureza.

Essa compreensão abre caminho para a consolidação de um Paradigma OntoEpistêmico do Campo (BARBOSA, 2019), erigido no âmbito das lutas empreendidas pelos povos indígenas e camponeses na América Latina. É justamente nesse processo educativo e político que se potencializa os processos de defesa dos territórios materiais e imateriais, de recuperação e socialização dos saberes ancestrais, dos saberes populares, como aporte fundamental no âmbito das lutas empreendidas em microcontextos e suas reverberações e articulações em outras escalas nacional e regional.

No contexto analisado, isto implica pensar um conjunto de desafios postos às escolas para uma abordagem educativa e pedagógica da agroecologia para além do contexto escolar ou de uma política educacional, uma vez que o que se almeja é a territorialização da agroecologia (ROSSET, 2017). Entre os desafios, destacamos (ROSSET, 2017):

Transformar essas escolas em eixos de ação para os processos territoriais de agroecologia;

Desenvolver métodos de ensino para uma recuperação e valorização dos saberes e conhecimentos ancestrais herdados do núcleo familiar e comunitário;

Transversalizar a agroecologia em toda a estrutura curricular, concedendo-lhe um enfoque agroecológico; 
Promoção do diálogo de saberes entre a diversidade de conhecimentos;

Transformar a escola em um epicentro de um processo agroecológico.

A análise das duas experiências educativas em microcontextos do campo demonstra o esforço de construção de uma concepção de educação e de um modelo pedagógico que transcendam a função social da escola na perspectiva das políticas públicas, por vezes restrita à formação escolar e para o mercado de trabalho. Sem abrir mão desta função social da escola, uma vez que os jovens desejam ter uma formação que concorra às possibilidades de ingresso na universidade ou no mercado de trabalho, também reivindicam que a escola possa reestabelecer a dimensão humanizadora em sua formação educativa. À luz das organizações indígenas e camponesas isto representa o reestabelecimento e fortalecimento do vínculo com seus territórios e a possibilidade de construção de um horizonte emancipatório.

\section{Considerações finais}

Nesse artigo tratamos de apresentar duas experiências educativas que se desenvolvem em microcontextos do campo mexicano e brasileiro. Em que pese os desafios de uma síntese das experiências em questão, consideramos que elas lançam luzes para pensarmos a que deveria responder, a priori, uma política nacional de educação elaborada e gerida pelos Estados nacionais.

Em outros termos, os microcontextos são fundamentais para identificarmos a concepção de educação articulada pelos diferentes sujeitos e, ao mesmo tempo, como são articuladas estratégias para a proposição de um modelo pedagógico que atenda não só a demanda educativa, mas também a demanda política das comunidades e suas organizações. Nessa direção, a Educação do Campo rebate a concepção de campo como um lugar do atraso, do arcaico, lugar onde não se efetiva nenhuma política pública de educação, pois não se tinha escola, ou quando essas existiam, não atendia a demanda educativa em sua totalidade, pois as condições eram precárias.

Ao se reivindicarem como sujeitos partícipes do processo de construção de uma proposta educativa e pedagógica, as comunidades indígenas e camponesas expressam seu desejo de que a educação cumpra seu papel social, no sentido de formar novas mulheres, novos homens e novas relações sociais entre si e com a natureza.

Como fruto da luta dos trabalhadores e trabalhadoras organizados, a educação do campo não tem somente construído uma nova realidade, mas também vem formando novos 
homens e mulheres. Destacamos que a Escola de Agricultura Ecológica U Yits Ka'na e a Escola de Ensino Médio João dos Santos de Oliveira são fruto de um processo social de questionamento profundo do caráter colonial ainda preponderante nas políticas públicas de educação. Nesse sentido, também podem ser consideradas experiências educativas de descolonização pedagógica, uma vez que reivindicam outras matrizes formativas que emergem de suas identidades, da cosmovisão e de seu vínculo com o território.

No que concerne aos desafios, além daqueles abordados no artigo, destacamos o desafio permanente de romper com o modelo imposto de educação tradicional e de seu caráter colonial e bancário. Por essa razão, as escolas primam por fortalecer a espiritualidade e a identidade coletiva como elementos fundamentais da organicidade do processo educativo dentro das escolas e de suas interfaces com a vida comunitária.

A experiências educativas analisadas apontam a centralidade de matrizes curriculares diferenciadas como uma estratégia de interpelação desse modelo educacional historicamente construído para atender aos anseios de uma racionalidade vinculada ao capitalismo. Nesse processo pedagógico, a agroecologia constitui uma matriz formativa fundamental para o fortalecimento do tecido comunitário e do próprio território sob a ótica indígena e camponesa.

AGRADECIMENTOS: Agradecemos à Bolsa BPV-FUNCAP que propiciou as condições necessárias para o desenvolvimento da pesquisa em áreas de assentamento rural no Ceará, Brasil.

\section{REFERÊNCIAS}

BARBOSA, L. P. As dimensões epistêmico-políticas da Educação do Campo em perspectiva latino-americana. Dossiê Educação do Campo: histórias, práticas e desafios. Revista Reflexão e Ação, Santa Cruz do Sul, n. 22, p. 143-169, jul./dez. 2014.

BARBOSA, L. P. Educação do Campo [Education for and by the countryside] as a political project in the context of the struggle for land in Brazil. The Journal of Peasant Studies, v. 44, n. 1, p. 118-143, 2017, DOI: http://doi.org/10.1080/03066150.2015.1119120

BARBOSA, L. P. Educação do Campo, movimentos sociais e a luta pela democratização da Educação Superior: os desafios da universidade pública no Brasil. In: SILVA, A. A et al. Los desafíos de la universidad pública en América Latina y el Caribe. Buenos Aires: CLACSO, 2015b. p. 147-212.

BARBOSA, L. P. Educación, resistencia y movimientos sociales: la praxis educativopolítica de los Sin Tierra y de los Zapatistas. México: LIBRUNAM, $2015 \mathrm{a}$. 
BARBOSA, L. P. Paradigma epistémico do campo e a construção do conhecimento na perspectiva dos movimentos indígenas e camponeses na América Latina. In: RAMOS, A. R. (Org.). Educação e movimentos sociais: análises e desafios. Jundiaí: Paco Editorial: 2019. p. 279-299.

BARBOSA, L. P.; ROSSET, P. M. Movimentos sociais e Educação do Campo na América Latina: aprendizagens de um percurso histórico. Revista Práxis Educacional, Vitória da Conquista, v. 13, n. 26, p. 22-48, 2017. DOI: https://doi.org/10.22481/praxis.v13i26.2819

CALDART, R. S. Pedagogia do Movimento Sem Terra. São Paulo: Expressão Popular, 2004.

CALDART, R. S.; STEDILE, M. E.; DAROS, D. Caminhos para a transformação da escola 2. Agricultura camponesa, educação politécnica e escolas do campo. São Paulo: Expressão Popular, 2015.

CEBALLOS, L. A. Experiencias y avances actuales: Escuela de agricultura ecológica U Yits Ka'an. In: MATA, G. B (Coord.). Escuelas campesinas en México. Diagnósticos y aportes a la educación rural alternativa. Estado de México: Universidad Autónoma Chapingo, 2014. p. 49-54.

FERNANDES, I. F.; BARBOSA, L. P. A construção da agroecologia no semiárido. A Metodologia de Camponês a Camponês no Assentamento Santana, Ceará, Brasil. In: SALINAS, R. T. et al. Senti-pensarnos tierra. Experiencias de transición y r-existencias en tiempos de crisis civilizatoria: voces desde los pueblos del Abya Yala. Buenos Aires: CLACSO, 2020. p. 72-80.

GALEANO, E. Memoria del fuego I. Los nacimientos. México: Siglo XXI Editores, 1991.

GÓMEZ-SOLLANO, M. Políticas y reformas educativas en México: tensiones y articulaciones. Revista O Público e O Privado, v. 15, n. 30, 2017, p. 17-35.

HERNÁNDEZ, G. F. Sistematización de la experiencia de la Escuela de Agricultura Ecológica $U$ Yits $K a^{\prime}$ an y su efecto sobre los medios de vida de las familias participantes en el municipio de Maní, Yucatán, México. 2015. Tesis (Maestría) - Centro Agronómico Tropical de Investigación y Enseñanza, Turrialba, Costa Rica, 2015. Disponível em:

http://repositorio.bibliotecaorton.catie.ac.cr/handle/11554/8214. Acesso em: 10 jul. 2020.

HOLT-JIMÉNEZ, E. Campesino a campesino. Voces de Latinoamérica. Movimiento campesino a campesino para la agricultura sustentable. Managua, Nicaragua: SIMAS, 2008.

MACHÍN-SOSA, B. et al. Revolução Agroecológica. O Movimento de Camponês a Camponês da ANAP em Cuba. São Paulo: Expressão Popular, 2013.

MACOSSAY, V. M. et al. La Escuela de Agricultura Ecológica U Yits Ka'an de Maní, Yucatán. Diez años de trabajo. Revista de Geografía Agrícola, n. 35, p. 91-104, 2005. Disponível em: https://www.redalyc.org/pdf/757/75703505.pdf. Acesso em: 10 jul. 2020. 
MATA, G. B. Nuestro caminar con las escuelas campesinas. In: MATA, G. B. (Coord.). Escuelas campesinas: 10 años en movimiento. Estado de México: Universidad Autónoma Chapingo, 2013. p. 23-44.

MST-CE. Caderno de Trabalho de Base do Setor de Educação do MST - CE, n. 04. Organizando o setor de Educação do MST Ceará. Julho de 2012.

MUÑOZ, S. P. Educación, desarrollo y saberes campesinos en Atenco, México. In: MATA, G. B. (Coord.). Escuelas campesinas: 10 años en movimiento. Estado de México:

Universidad Autónoma Chapingo, 2013. p. 213-224.

PPP. PROJETO POLÍTICO PEDAGÓGICO. Escola de Ensino Médio do Campo João dos Santos. Assentamento 25 de Maio, Madalena. Ceará: Setor de Educação do MST-Ceará, 2010 .

RIBEIRO, D. S. et al. Agroecologia na Educação Básica. Questões propositivas de conteúdo e metodologia. São Paulo: Expressão Popular, 2017.

ROSSET, P. A territorialização da Agroecologia na disputa de projetos e os desafios para as escolas do campo. In: RIBEIRO, D. S.; TIEPOLO, E. V.; VARGAS, M. C.; SILVA, N. R. Agroecologia na Educação Básica. Questões propositivas de conteúdo e metodologia. São Paulo: Expressão Popular, 2017. p. 117-126.

SAPELLI, M. L. S.; FREITAS, L. C.; CALDART, R. S. Caminhos para a construção da escola 3. Organização do trabalho pedagógico nas escolas do campo: ensaios sobre os complexos de estudo. São Paulo: Expressão Popular, 2015.

SUÁREZ, C. M. G. El convento de Maní, Yucatán, en 1588. Boletín de Monumentos Históricos, Tercera época, n. 31, p. 78-92, 2014. Disponível em: http://boletincnmh.inah.gob.mx/boletin/boletines/bmh\%2031-5.pdf. Acesso em: 10 jul. 2020.

\section{Como referenciar este artigo}

LÓPEZ VALENTÍN, R.; ROSSET, P. M.; PINHEIRO BARBOSA, L.; LOBO CASTRO, C. A. Por um modelo pedagógico para uma educação agroecológica em perspectiva camponesa e indígena: avanços, tensões e desafios no Brasil e no México. Revista Ibero-Americana de Estudos em Educação, v. 16, n. esp. 2, p. 1215-1230, maio 2021. e-ISSN: 1982-5587. DOI: https://doi.org/10.21723/riaee.v16iesp2.15122

Submissão em: $15 / 12 / 2020$

Revisões requeridas em: 28/01/2021

Aprovado em: 03/03/2021

Publicado em: 01/05/2021 